\title{
Implementasi pembelajaran Pendidikan Agama Islam menggunakan video cerita dalam pembentukan karakter siswa yang islami
}

\author{
Muh. Arifin \\ SDN 02 Talun Kabupaten Pekalongan
}

\begin{tabular}{ll}
\hline Article Info & ABSTRACT \\
\hline Article history: & $\begin{array}{l}\text { Islamic Religious Education (PAI) is one of the compulsory subjects ranging } \\
\text { from basic to higher education for followers of the Islamic religion. The } \\
\text { purpose of this study is to implement Islamic religious education learning }\end{array}$ \\
Received : 16 Agustus 2021 & $\begin{array}{l}\text { using video stories in the formation of Islamic characters. This type of } \\
\text { revearch is Classroom Action Research (CAR) with four stages of } \\
\text { Accepted : } 30 \text { September 2021 }\end{array}$ \\
\hline implementation. The subjects in this study were 18th graders of SDN 02 \\
Talun. Data collection techniques in this study were obtained from \\
interviews, written test observations and documentation. The data obtained \\
were analyzed by calculating the average mastery of individual and classical \\
learning. The success indicator in this study is for individual learning \\
completeness if the proportion of students' correct answers is more than the \\
predetermined KKM and for classical learning completeness if at least $85 \%$ \\
of all students have reached the KKM. The results of this study are in cycle \\
1, students whose scores reach the minimum completeness criteria are 14 \\
students with a percentage of $77.78 \%$. Then for students who have not \\
achieved completeness at least 4 students with a percentage of $22.22 \%$. For \\
cycle 2, students whose scores reach the minimum completeness criteria are \\
16 students with a percentage of $88.89 \%$. Then for students who have not \\
achieved completeness, there are at least 2 students with a percentage of \\
$11.11 \%$ as well. So it can be concluded that the use of video stories can \\
increase the formation of Islamic characters.
\end{tabular}

(*) Corresponding Author:

arifinapv@gmail.com

How to Cite: Arifin, M. (2021). Implementasi pembelajaran Pendidikan Agama Islam menggunakan video cerita dalam pembentukan karakter siswa yang islami. Action Research Journal, 1(1): 82-87.

\section{PENDAHULUAN}

UU No. 20 Tahun 2003 tentang Sistem Pendidikan Nasional menyatakan pendidikan merupakan usaha sadar dan terencana yang dilakukan dalam rangka mewujudkan suasana belajar dan proses pembelajaran agar siswa secara aktif mengembangkan potensi dirinya untuk memiliki kekuatan spiritual keagamaan, pengendalian diri, kepribadian kecerdasan, akhlak mulia, serta keterampilan yang diperlukan dirinya, masyarakat, bangsa dan negara. Untuk itulah dibutuhkan pendidikan yang mendukung dari tujuan pendidikan Nasional.

Pendidikan Agama Islam (PAI) merupakan salah satu mata pelajaran wajib mulai dari pendidikan dasar sampai tinggi bagi pemeluk agama islam. Elihami dan Abdullah (2018) menyatakan PAI merupakan proses ikhtiyariyah yang memiliki ciri dan watak khusu yaitu proses penanaman, pengembangan dan pemantapan nilai-nilai keimanan yang menjadi dasar mental-spiritual manusia dimana sikap dan tingkah lakunya termanifestasi menurut kaidahkaidah agamanya. PAI juga melatih kepekaan siswa sehingga sikap dan perilaku siswa didominasi oleh nilai etis dan spiritual islam (Mudhafir, 2000). Daradjat (2015) mengatakan bahwa PAI adalah usaha berupa bimbingan dan asuhan terhadap anak agar kelak setelah selesai pendidikannya dapat memahami dan mengamalkan ajaran agama Islam serta menjadikannya sebagai way of life. 
Musya'Adah (2018) menyatakan PAI mempunyai tujuan-tujuan yang berisi tiga aspek yaitu: (1) menumbuhkan dan mengembangkan serta membentuk sikap yang baik dan disiplin serta cinta terhadap agama dalam berbagai kehidupan anak nantinya diharapkan menjadi manusia yang bertakwa kepada Allah SWT dan Rasul-Nya; (2) ketaatan kepada Allah SWT dan Rasul-Nya merupakan motivasi intrinsik terhadap perkembangan ilmu pengetahuan yang harus dimiliki oleh seorang anak. Dengan kata lain, tujuan pada aspek ilmu ini ialah pengembangan pengetahuan agama, yang dengan pengetahuan itu dimungkinkan pembentukan pribadi yang berakhlak mulia, yang bertaqwa kepada Allah SWT, sesuai dengan ajaran islam dan mempunyai keyakinan yang mantap kepada Allah SWT; (3) menumbuhkan dan membina ketrampilan beragama dalam semua lapangan hidup dan kehidupan serta dapat memahami dan menghayati.

Dalam proses pembelajaran PAI di kelas, dibutuhkan kreativitas dari seorang guru, karena guru merupakan vasilitator yang mampu mengelola kegiatan akademik, memberikan masukan atau ide kepada siswa dalam menyelesaikan permasalahan, dan memberikan evaluasi yang sesuai dengan materi pembelajaran (Musya'Adah, 2018). Salah satu bentuk kreativitas guru dalam proses pembelajaran di kelas adalah penggunaan media pembelajaran yang sesuai.Media pembelajaran adalah segala sesuatu yang memungkinkan siswa memperoleh pengetahuan dan keterampilan. Dengan kata lain, bahwa media adalah alat bantu apa saja yang dapat dijadikan sebagai penyalur pesan guna mencapai tujuan pembelajaran. Djamarah dan Aswan Zain (2002) menyatakan media audio visual adalah salah satu media pembelajaran yang mempunyai unsur suara dan unsur gambar. jenis media ini mempunyai kemampuan yang lebih baik karena meliputi suara dan gambar. Video merupakan media audio visual yang sudah beredar di masyarakat dan banyak diminati oleh anak-anak sekolah dasar, mulai dari jenis video hiburan, pengetahuan, informasi, musik, dan cerita-cerita bersejarah bisa disaksikan dengan mudah.

Dalam mata pelajaran PAI, diperlukan video pembelajaran berupa teladan-teladan para sahabat Nabi. Perlu dipahami bahwa Keteladanan merupakan sebuah metode pendidikan Islam yang sangat efektif yang diterapkan oleh seorang guru dalam proses pendidikan. Karena dengan adanya pendidikan keteladanan akan mempengaruhi individu pada kebiasaan, tingkah laku dan sikap (Mustofa, 2019). Berdasarkan pengalaman guru selama ini, nilai prasiklus siswa kelas V SDN 02 Talun terkait dengan pembentukan karakter islami masih rendah. Hal tersebut didukung oleh Tabel 1 sebagai berikut.

Tabel 1. Nilai prasiklus siswa kelas V SDN 02 Talun

\begin{tabular}{lc}
\hline \multicolumn{1}{c}{ Keterangan } & Nilai Siswa \\
\hline Nilai Tertinggi & 88 \\
Nilai Terendah & 40 \\
Nilai Rata-rata & 69 \\
Jumlah Siswa dengan nilai $0.00-<20,00$ & - \\
Jumlah Siswa dengan nilai $20,00-<40,00$ & 2 \\
Jumlah Siswa dengan nilai $40,00-<60,00$ & 4 \\
Jumlah Siswa dengan nilai $60,00-<80,00$ & 10 \\
Jumlah Siswa dengan nilai $80,00-<100,00$ & 2 \\
Jumlah Siswa & 18 \\
Persentase siswa yang tuntas (nilai $\geq 75)$ & 50 \\
\hline
\end{tabular}

Dari Tabel 1 diatas, terlihat bahwa siswa yang telah memenuhi ketuntasan belajar dengan persentase ketuntasan 50\%. Untuk itulah diperlukan kreativitas guru dalam meningkatkan perkembangan nilai karakter siswa yang islami melalui penggunaan media video pembelajaran di SDN 02 Talun.

\section{METODE}

Penelitian ini dilakukan pada siswa kelas V SDN 02 Talun. Karena sedang dalam masa pandemi Covid-19, maka pelaksanaan penelitian ini dilakukan intensif secara daring. Subjek dalam penelitian ini berjumlah 18 siswa. Jenis penelitian ini adalah Penelitian Tindakan Kelas 
(PTK) dengan dua siklus. Hasil penelitian ini menitikberatkan pada nilai kuantitatif karakter siswa yang islami.Adapun model PTK dan masing-masing tahap dapat dinyatakan dalam Gambar 1 sebagai berikut.

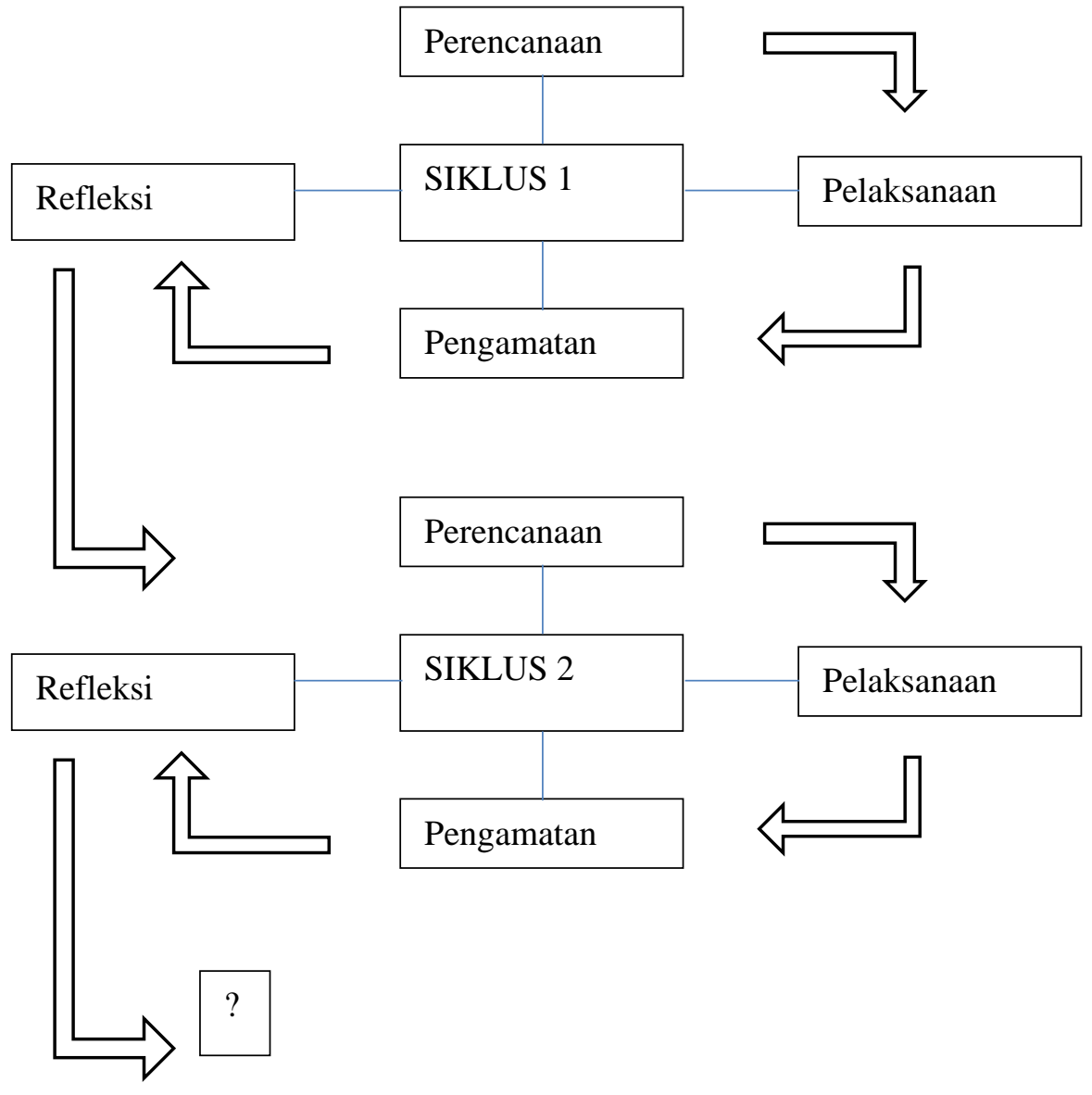

Gambar 1. Pelaksanaan PTK

Berdasarkan diagram diatas diatas, maka penjelasan untuk masing-msing tahapan dalam siklus sebagai berikut.

1. Perencanaan

a. Membuat rencana pelaksanaan pembelajaran (RPP) beserta skenario tindakan yang akan dilaksanakan menggunakan video pembelajaran;

b. Menyiapkan video pembelajaran

c. Menyiapkan lembar kegiatan siswa dan lembar kerja siswa

d. Menyusun lembar observasi siswa

2. Pelaksanaan

a. Secara daring, guru melaksanakan apersepsi yaitu guru bertanya tentang aktivitas siswa tadi pagi sejak bangun tidur sampai berangkat sekolah.Salah seorang siswa diminta menceritakan aktivitasnya pagi itu;

b. Guru mempersiapkan video pembelajaran sesuai dengan tujuan pembelajaran;

c. Siswa diminta untuk memperhatikan video pembelajaran yang telah disiapkan oleh guru;

d. Siswa diberi petunjuk dan diberi kesempatan untuk memperhatikan atau menganalisis video tersebut.

e. Siswa dibentuk kelompok terdiri dari 3 s.d. 4 siswa dan setiap kelompok diberi kesempatan untuk membacakan hasil diskusi; 
f. Setelah berdiskusi dan memaparkan hasilnya, guru mulai menjelaskan materi sesuai dengan tujuan yang ingin dicapai;

g. Siswa secara individu menulis hasil diskusi dan pembahasan berdasarkan video yang ditayangkan dan dikumpulkan melalui daring.

3. Pengamatan

Selama kegiatan pembelajaran, observer mengamati dan mencatat hasil dalam lembar observasi yang digunakan sebagai dasar refleksi setiap siklus dan dipadukan dengan hasil evaluasi.

4. Refleksi

Hasil yang diperoleh dari pengamatan dan hasil evaluasi pada tindakan siklus I digunakan sebagai dasar apakah sudah memenuhi target atau perlu dilakukan penyempurnaan pada pengorganisasian pembelajaran agar siklus II diperoleh hasil yang lebih baik, begitu seterusnya.

Teknik pengumpulan data pada penelitian ini diperoleh dari wawancara, observasi tes tertulis dan dokumentasi. Data yang diperoleh dianalisis dengan menghitung rata-rata ketuntasan belajar individual maupun klasikal. Indikator keberhasilan pada penelitian ini adalah untuk ketuntasan belajar individu jika proporsi jawaban benar siswa lebih dari KKM yang telah ditetapkan dan untuk ketuntasan belajar klasikal jika minimal $85 \%$ dari seluruh siswa telah mencapai KKM.

\section{HASIL DAN PEMBAHASAN}

Hasil

Nilai kuantitatif mata pelajaran PAI pada siswa kelas V SDN 02 Talun diukur berdasarkan hasil nilai post test yang dilakukan pada siklus 1 dan siklus 2 . Evaluasi pada setiap siklus dilakukan menggunakan instrumen soal tes sebanyak 20 soal pilihan ganda. Soal tersebut diberikan setelah proses pembelajaran menggunakan media video pembelajaran yang telah disiapkan oleh guru. Siklus 1 dilaksanakan pada tanggal 28September s.d. 16 Oktober 2020 pada jam mata pelajaran PAI. Sementara untuk siklus 2 dilaksanakan pada tanggal 19 Oktober s.d. 6 November 2020.

Tabel 2. Rekapitulasi hasil tes pra siklus

\begin{tabular}{lc}
\hline \multicolumn{1}{c}{ Uraian } & Pra Siklus \\
\hline Nilai rata-rata tes & 69,00 \\
Jumlah siswa yang tuntas belajar & 9 \\
Jumlah siswa yang belum tuntas belajar & 9 \\
Persentase siswa yang tuntas belajar & 50,00 \\
Persentase siswa yang belum tuntas belajar & 50,00 \\
\hline
\end{tabular}

Berdasarkan data pada Tabel 2, dapat dilihat bahwa siswa yang nilainya mencapai kriteria ketuntasan minimal berjumlah 9 siswa dengan persentase 50\%. Kemudian untuk siswa yang belum mencapai ketuntasan minimal berjumlah 9 siswa dengan persentase $50 \%$ juga. Angka tersebut masih jauh dari indikator keberhasilan yang ditetapkan yaitu sebesar $85 \%$ dari seluruh siswa yang memperoleh nilai diatas KKM. Untuk itulah, diberi perlakuan dalam siklus 1 dengan hasil yang dapat dilihat pada Tabel 3 sebagai berikut.

Tabel 3. Rekapitulasi hasil tes siklus 1

\begin{tabular}{lc}
\hline \multicolumn{1}{c}{ Uraian } & Siklus 1 \\
\hline Nilai rata-rata tes & 78,50 \\
Jumlah siswa yang tuntas belajar & 14 \\
Jumlah siswa yang belum tuntas belajar & 4 \\
Persentase siswa yang tuntas belajar & 77,78 \\
Persentase siswa yang belum tuntas belajar & 22,22 \\
\hline
\end{tabular}

Berdasarkan data pada Tabel 3, dapat dilihat bahwa siswa yang nilainya mencapai kriteria ketuntasan minimal berjumlah 14 siswa dengan persentase $77,78 \%$. Kemudian untuk 
siswa yang belum mencapai ketuntasan minimal berjumlah 4 siswa dengan persentase $22,22 \%$ juga. Angka tersebut sudah meningkat dibanding dengan data pra siklus, tetapi masih belum memenuhi indikator keberhasilan yang ditetapkan yaitu sebesar $85 \%$ dari seluruh siswa yang memperoleh nilai diatas KKM. Untuk itulah, diberi perlakuan dalam siklus 2 dengan hasil yang dapat dilihat pada Tabel 4 sebagai berikut.

Tabel 4. Rekapitulasi hasil tes siklus 2

\begin{tabular}{lc}
\hline \multicolumn{1}{c}{ Uraian } & Siklus 2 \\
\hline Nilai rata-rata tes & 84,50 \\
Jumlah siswa yang tuntas belajar & 16 \\
Jumlah siswa yang belum tuntas belajar & 2 \\
Persentase siswa yang tuntas belajar & 88,89 \\
Persentase siswa yang belum tuntas belajar & 11,11 \\
\hline
\end{tabular}

Berdasarkan data pada Tabel 4, dapat dilihat bahwa siswa yang nilainya mencapai kriteria ketuntasan minimal berjumlah 16 siswa dengan persentase $88,89 \%$. Kemudian untuk siswa yang belum mencapai ketuntasan minimal berjumlah 2 siswa dengan persentase $11,11 \%$ juga. Angka tersebut sudah memenuhi indikator keberhasilan yang ditetapkan yaitu sebesar $85 \%$ dari seluruh siswa yang memperoleh nilai diatas KKM. Untuk rata-rata tes siswa sebesar 84,50 . Sehingga tidak perlu dilanjutkan ke siklus selanjutnya.

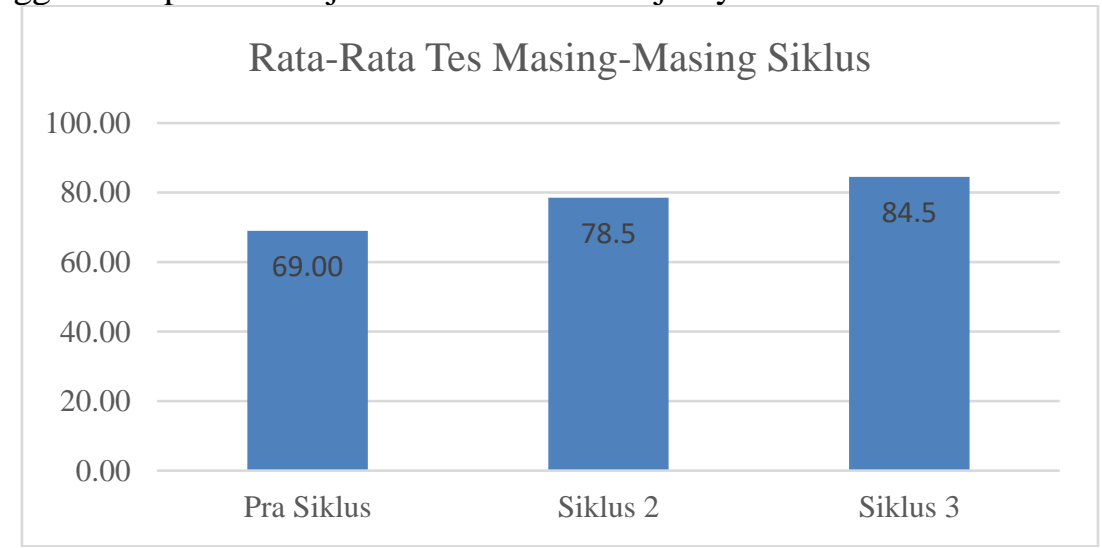

Diagram 2. Persentase rata-rata tes masing-masing siklus

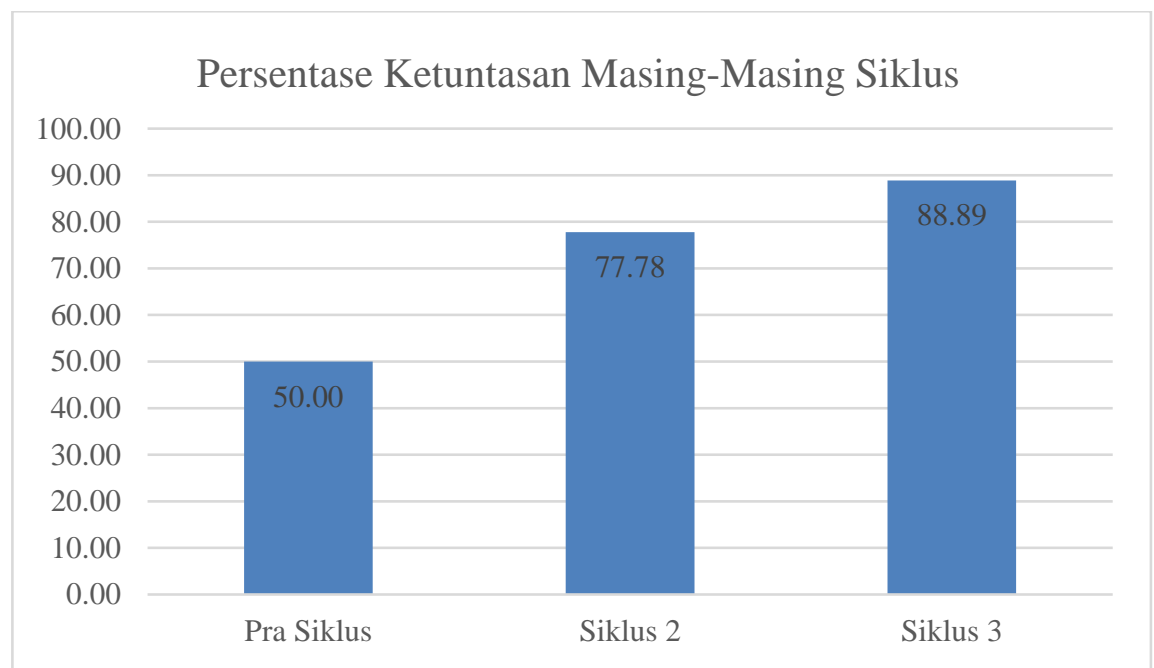

Diagram 3. Persentase ketuntasan masing-masing siklus

Berdasarkan hasil penelitian ini, dapat dilihat bahwa pembelajaran menggunakan video pembelajaran ketaladan sahabat Rosul dapat meningkatkan rata-rata tes dalam pembentukan karakter islami siswa sebagaimana dapat dilihat pada diagram 2. Mustofa (2019) menyatakan 
bahwa pada fase anak-anak merupakan fase paling cocok, paling panjang, dan paling penting untuk ditanamkan prinsip-prinsip yang baik, lurus dan diarahkan jalan yang benar ke dalam jiwa dan perilaku anak. Sependapat dengan pernyataan diatas, Ramayulis (2010) menyatakan bahwa anak merupakan peniru yang ulung, sifat meniru ini merupakan metode yang positif dalam pendidikan keagamaan pada anak. Anirah (2013) menyatakan bahwa dalam berbagai hal dalam pendidikan, keteladanan pendidik merupakan metode pendididikan yang sangat penting, bahkan yang paling utama. Sehubungan dengan ini, Allah SWT berfiman:

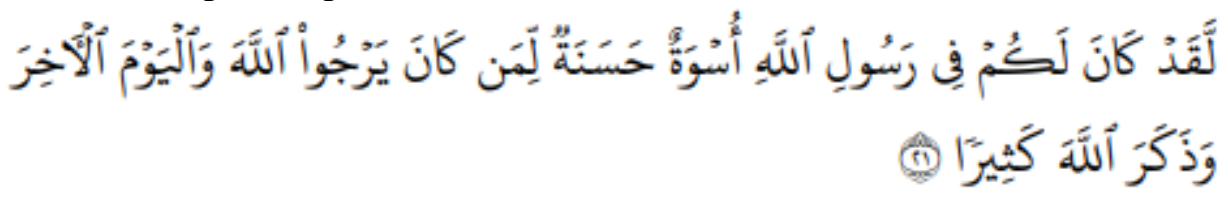

"Sesungguhnya telah ada pada (diri) Rasulullah itu suri teladan yang baik bagimu (yaitu) bagi orang yang mengharap (rahmat) Allah dan (kedatangan) hari kiamat dan Dia banyak menyebut Allah (Q.S. Al Ahzab 21)”.

\section{PENUTUP}

Berdasarkan hasil penelitian diatas, dapat disimpulan bahwa penggunaan video cerita dalam pembentukan karakter yang Islami dapat meningkatkan pembentukan karakter yang islami. Hal ini diperkuat oleh hasil dari siklus 1 yang mencapai kriteria ketuntasan minimal berjumlah 14 siswa dengan persentase $77,78 \%$. Sementara untuk hasil dari siklus 2 mencapai kriteria ketuntasan minimal berjumlah 16 siswa dengan persentase $88,89 \%$. Saran yang dapat dikemukakan adalah hendaknya guru dapat meningkatkan kemampuan dalam berinovasi dalam pembuatan media pembelajaran seperti video cerita agar proses pembelajaran lebih menarik dan dapat mencapai tujuan pembelajaran.

\section{DAFTAR PUSTAKA}

Anirah, A. (2013). Metode Keteladanan Dan Signifikansinya Dalam Pendidikan Islam. Fikruna. 2(1).

Depdiknas. (2003). Undang-Undang RI No.20 tahun 2003.tentang Sistem Pendidikan Nasional.

Djamarah, S. B., \& Aswan, Z. (2002).Strategi Belajar Mengajar. Jakarta: PT Rineka Cipta.

Elihami, E., Syahid, A. (2018). Penerapan Pembelajaran Pendidikan Agama Islam dalam Membentuk Karakter Pribadi yang Islami. Edumaspul - Jurnal Pendidikan, 2(1), 79-96.

Fadhlan Mudhafir. (2000).Krisis Dalam Pendidikan Islam (Cet. I). Jakarta: Al-Mawardi Prima.

Mustofa, Ali. (2019). Metode keteladanan perspektif pendidikan islam. Cendekia: Jurnal Studi Keislaman. 5 (1), Juni 2019. P-ISSN. 2443-2741. E-ISSN. 2579-5503

Musya'Adah, U. (2018). Peran Penting Pendidikan Agama Islam di Sekolah Dasar. AULADA: Jurnal Pendidikan dan Perkembangan Anak. e-ISSN: 2656-1638. I,(2).

Ramayulis. (2006). Ilmu Pendidikan Islam. Jakarta: Kalam Mulia.

Zakiyah Daradjat. (2015).Ilmu Pendidikan Islam. Jakarta: PT Bumi Aksara. 